\title{
Crystals in the bowel: culprit or curiosity?.
}

Shaadi Abughazaleh, MD ${ }^{*}$, Daniel S. Zhang, MD², Mary R. Schwartz, MD ${ }^{3}$, Sudha Kodali, MD ${ }^{2,4}$

${ }^{1}$ Department of Internal Medicine, Houston Methodist Hospital, Houston, Texas

${ }^{2}$ Division of Gastroenterology, Department of Medicine, Houston Methodist Hospital, Houston, Texas

${ }^{3}$ Department of Pathology and Genomic Medicine, Houston Methodist Hospital, Houston, Texas

${ }^{4}$ Sherrie and Alan Conover Center for Liver Disease, Houston Methodist Hospital, Houston, Texas

*Corresponding author: Sudha Kodali, Sherrie and Alan Conover Center for Liver Disease, Houston Methodist Hospital, Houston, Texas.

Received date: June 01, 2020; Accepted date: June 29, 2020; Published date: July 06, 2020

Citation: Abughazaleh S., Daniel S. Zhang., Massey D., Mary R. Schwartz., David W. Victor., Kodali S., (2020) Fungki Ulcers. J. Archives of Medical Case Reports and Case Study. 3(1); DOI:10.31579/2692-9392/011

Copyright: ( 2020 Sudha Kodali, This is an open access article distributed under the Creative Commons Attribution License, which permits unrestricted use, distribution, and reproduction in any medium, provided the original work is properly cited.

\section{Abstract}

A 35-year-old female with end-stage renal disease on peritoneal dialysis presented with altered mental status and abdominal discomfort. On admission, she was found to have a distended tympanic abdomen and elevated WBC.

A 35-year-old female with end-stage renal disease on peritoneal dialysis presented with altered mental status and abdominal discomfort. On admission, she was found to have a distended tympanic abdomen and elevated WBC. After a CT of abdomen and pelvis demonstrated free air, the patient was taken emergently to the OR for diagnostic laparoscopy which revealed bilious peritonitis and a $5 \mathrm{~mm}$ perforation in the distal ileum. She underwent a right hemicolectomy with ileocolonic anastomosis. The resected bowel had multifocal ulceration (Figure 1). Microscopic examination demonstrated diffuse acute serositis associated with fungal organisms compatible with Candida species (Figure 2). There were focal two-toned crystals with fish scale pattern having characteristic features of sevelamer crystals (Figure 3,4). The patient had previously received sevelamer for treatment of hyperphosphatemia related to endstage renal disease. The potential etiologic role of sevelamer in the development of bowel ischemia, ulceration and perforation is not clear. The patient was treated with anti-fungal medications and had subsequent resolution of peritonitis.

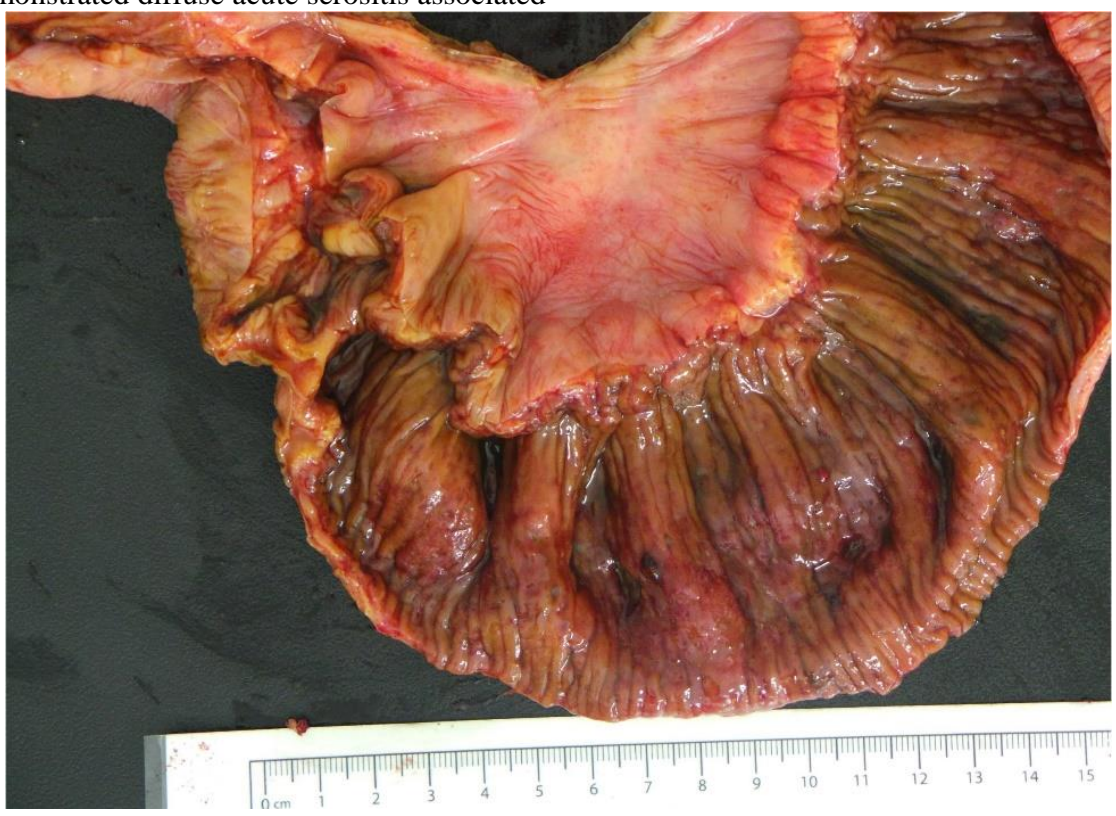

Figure 1. Resected terminal ileum and right colon showing multiple ulcers and thickened bowel with thickened folds, correlating with the bowel changes seen on CT scan 


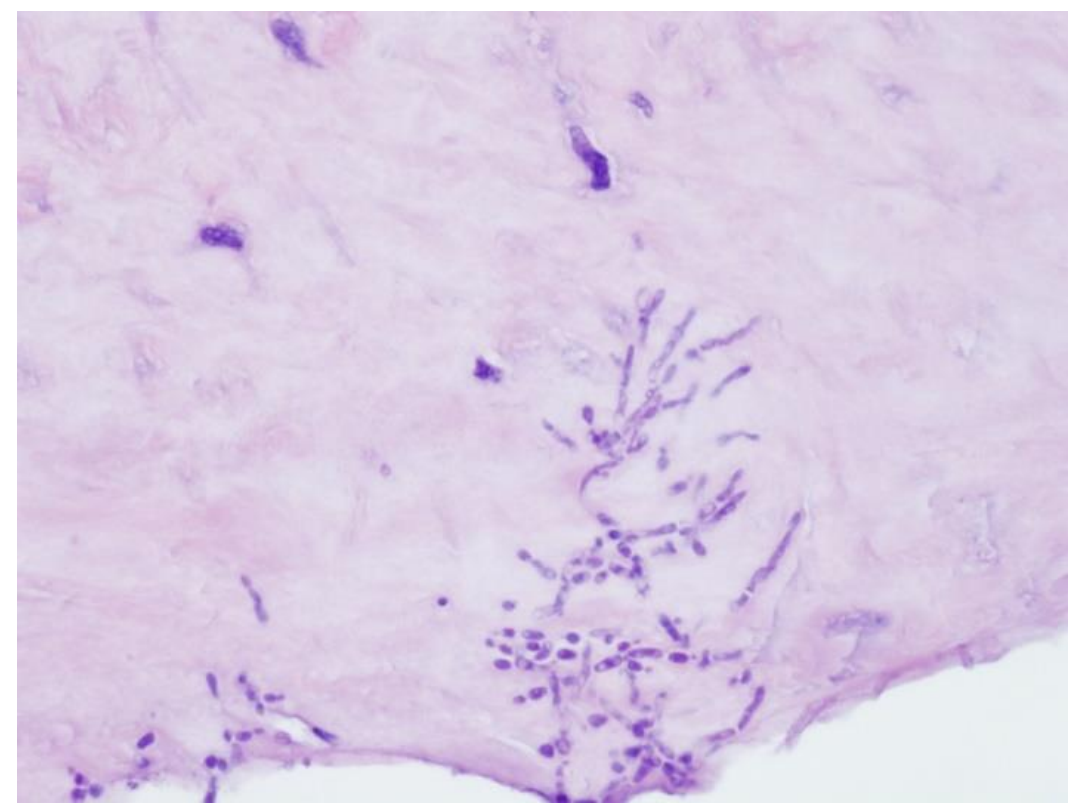

Figure 2. Diffuse serositis associated with fungal organisms compatible with Candida species(40x)

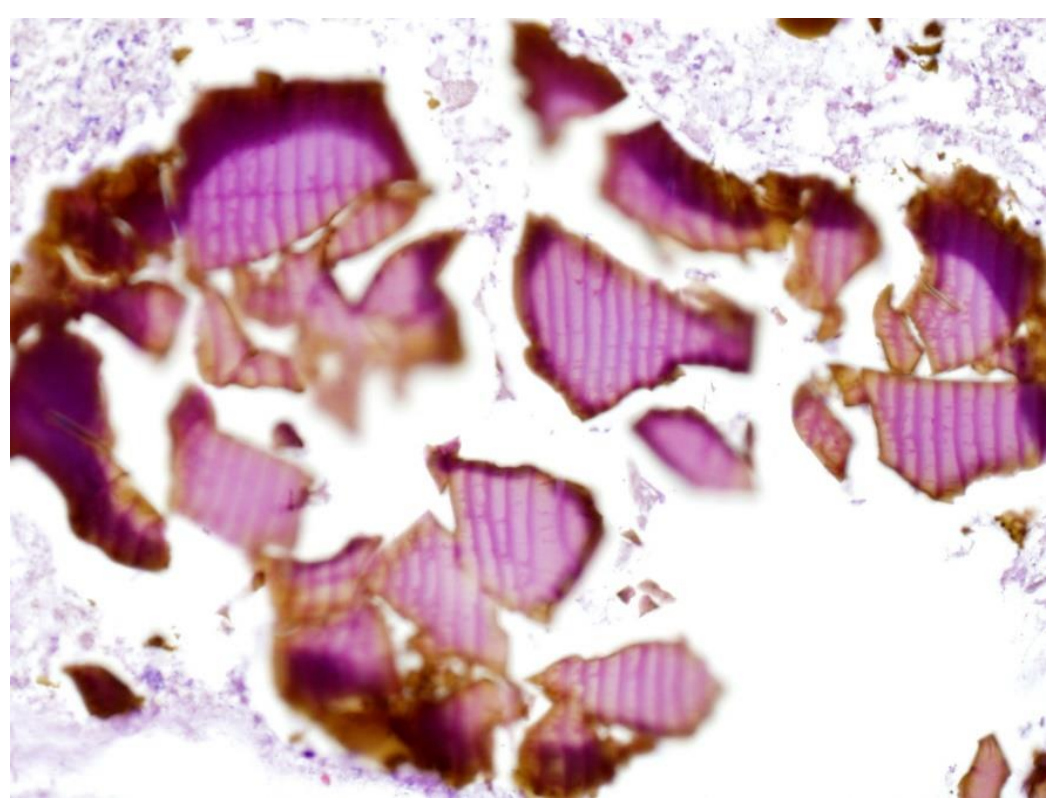

Figure 3. Numerous sevelamer crystals with classic two-toned color and fish scale pattern (20x) 


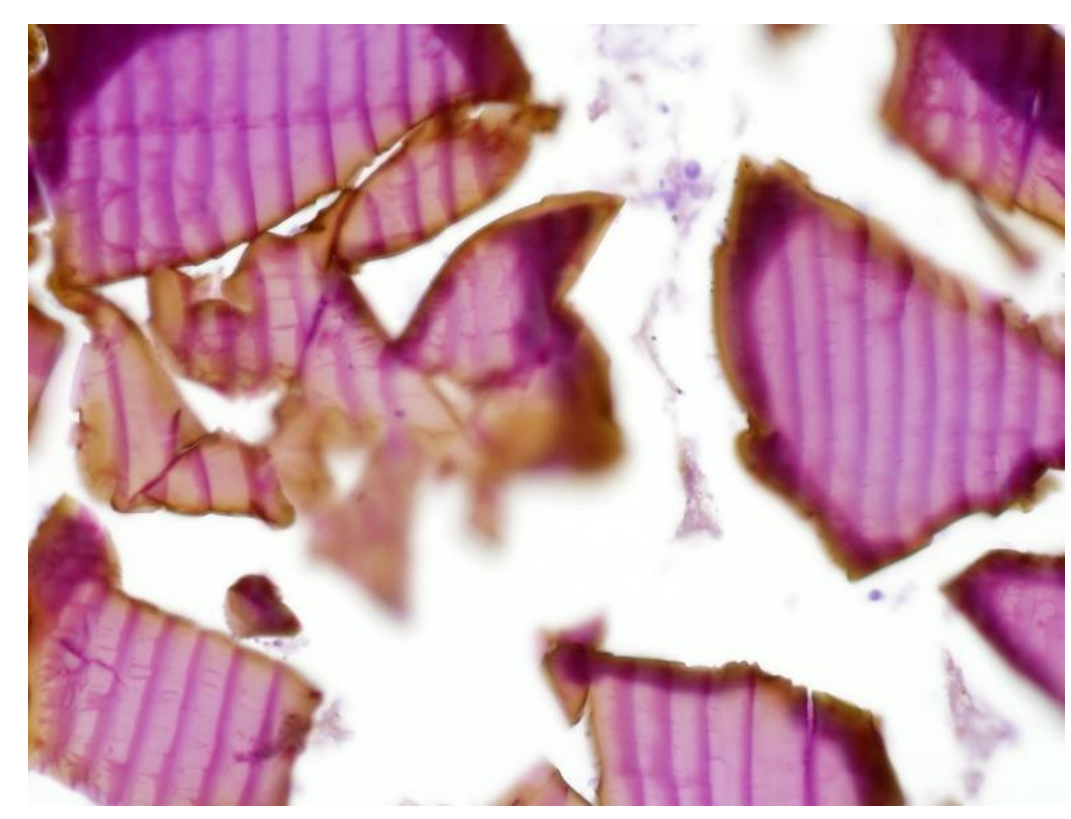

Figure 4. Higher power of sevelamer crystals showing classic irregularly spaced fish scale pattern (40x)

\section{Disclosures:}

Author contributions: S. Abughazaleh, D. Zhang, M. Schwartz, and S. Kodali wrote the manuscript.

$\mathrm{S}$. Kodali is the article guarantor. No financial support/competing interests. No conflict of interest. No previous presentations. Informed consent was obtained for this case report.

\section{Reference :}

1. Swanson BJ, Limketkai BN, Liu T-C, Montgomery E, Nazari $\mathrm{K}$, et al. 2013. Sevelamer crystals in the gastrointestinal
tract(GIT): a new entity associated with mucosal injury. Am J Surg Pathol 37(11):1686- 93

2. Yuste C, Merida E, Hernandez E, Garcia-Santiago A, Rodriguez Y, Munoz T, Gomez GJ, Sevillano A, Praga M. Gastrointestinal complications induced by sevelamer crystals. Clin Kidney J. 2017;10:539-44.
This work is licensed under Creative Commons Attribution 4.0 License

To Submit Your Article Click Here: Submit Article
Ready to submit your research? Choose Auctores and benefit from:

* fast, convenient online submission

* rigorous peer review by experienced research in your field

* rapid publication on acceptance

* authors retain copyrights

* unique DOI for all articles

* immediate, unrestricted online access

At Auctores, research is always in progress.

Learn more www.auctoresonline.org/journals/archives-of-medical-casereports-and-case-study 